\title{
The prevalence of ADH1B and OPRM1 alleles predisposing for alcohol consumption are increased in the Hungarian psoriasis population
}

\author{
Zita Szentkereszty-Kovács ${ }^{1} \cdot$ Szilvia Fiatal $^{2} \cdot$ Andrea Szegedi $^{1,3}$. Dóra Kovács ${ }^{1}$. Eszter Janka ${ }^{1} \cdot$ Krisztina Herszényi $^{4}$. \\ Péter Holló $^{4}$ • Pernilla Nikamo ${ }^{5}$. Mona Ståhle ${ }^{5}$. Éva Remenyik ${ }^{1}$. Dániel Töröcsik ${ }^{1,5}$
}

Received: 11 May 2018 / Revised: 25 February 2019 / Accepted: 22 March 2019 / Published online: 22 April 2019

(c) The Author(s) 2019

\begin{abstract}
Alcohol intake affects in great the symptoms and life of psoriasis patients, although the association of SNPs related to increased alcohol consumption with psoriasis has not been elucidated. Therefore, to investigate the association of psoriasis with established alcohol consumption and dependence-related gene variants we conducted a population-based case-control study including 3743 subjects (776 psoriasis cases and 2967 controls from the general Hungarian population). Genotyping of 23 SNPs at ADH1B, ADH1C, ALDH1A1, ALDH2, SLC6A3, DDC, GABRA2, GABRG1, HTR1B, MAOA, TPH2, CHRM2, GRIN2A, POMC, OPRM1, OPRK1 and BDNF were determined and differences in genotype and allele distributions were investigated. Multiple logistic regression analyses were implemented. Analysis revealed association between $\mathrm{C}$ allele of the rs 1229984 polymorphism $(A D H 1 B$ gene $)$ and psoriasis risk $\left(\mathrm{OR}_{\text {additive }}=1.58,95 \% \mathrm{CI} 1.23-2.03, p<0.001, \mathrm{OR}_{\text {recessive }}=1.58\right.$, 95\% CI 1.22-2.04, $p=0.001$ ). Furthermore, the $\mathrm{G}$ allele of rs 1799971 polymorphism (OPRM1 gene) increased the risk of familial aggregation $\left(\mathrm{OR}_{\text {additive }}=1.99,95 \%\right.$ CI 1.36-2.91, $p<0.001 \mathrm{OR}_{\text {dominant }}=2.01,95 \%$ CI $\left.1.35-3.01, p<0.001\right)$. In subgroups of psoriatic patients with history of early onset and familial aggregation effect allele ' $\mathrm{C}$ ' of rs 1229984 showed association in the additive and recessive models $\left(\mathrm{OR}_{\text {additive }}=2.41,95 \% \mathrm{CI} 1.26-4.61, p<0.01, \mathrm{OR}_{\mathrm{recessive}}=2.42,95 \% \mathrm{CI}\right.$ $1.26-4.68, p<0.01)$. While effect allele ' $\mathrm{G}$ ' of rs1799971 (OPRM1) also associated with increased risk of early onset and familial aggregation of psoriasis in the additive and dominant models $\left(\mathrm{OR}_{\text {additive }}=1.75,95 \%\right.$ CI $1.27-2.43, p=0.001$, $\mathrm{OR}_{\text {dominant }}=1.82,95 \%$ CI $\left.1.26-2.63, p=0.001\right)$. Our results suggest that genetically defined high-risk individuals for alcohol consumption are more common in the psoriasis population.
\end{abstract}

Keywords Psoriasis $\cdot$ Alcohol consumption $\cdot$ ADH1B gene $\cdot$ OPRM1 gene $\cdot$ Population genetics

Electronic supplementary material The online version of this article (https://doi.org/10.1007/s00403-019-01915-y) contains supplementary material, which is available to authorized users.

Dániel Törő́csik

dtorocsik@gmail.com

1 Department of Dermatology, Faculty of Medicine, University of Debrecen, Debrecen, Hungary

2 Department of Preventive Medicine, Faculty of Public Health, University of Debrecen, Debrecen, Hungary

3 Division of Dermatological Allergology, Faculty of Medicine, University of Debrecen, Debrecen, Hungary

4 Department of Dermatology, Venereology and Dermatooncology, Semmelweis University, Budapest, Hungary

5 Unit of Dermatology and Venereology, Department of Medicine, Karolinska Institutet, Karolinska University Hospital, Stockholm, Sweden

\section{Introduction}

Psoriasis is a common chronic inflammatory disease affecting $1-4 \%$ of the world population, with strong genetic as well as environmental factors in the background [32] affecting the onset, clinical manifestation and the course of the disease [6]. While the genetic association with the HLA-Cw6 allele and the nearly 40 risk regions revealed by recent GWAS studies confirm a pivotal role for the immune system [31, 33], the extent and mechanisms for gene-environment interactions in contributing to the pathogenesis or the increased risk for various comorbidities remains to be elucidated.

Alcohol consumption is one of the primary environmental factors, showing a direct link with psoriatic risk $[3,11,20$, $37,49,50]$, although further studies are needed to confirm if excessive alcohol consumption correlates with disease 
severity [17, 27, 36, 51]. Alcohol intake may affect psoriasis at various levels from the lower compliance of alcoholic patients to its interaction with the metabolism of therapeutic drugs [18]. Moreover, alcohol was shown to have a direct effect on immune cells and keratinocytes promoting their psoriasis related phenotype [12-14]. Still, at least to our knowledge, no studies were carried out to investigate the possible genetic background for alcohol consumption in psoriasis populations, to explore whether psoriatic patients have a genetically increased risk for alcohol consumption.

Heritability in alcohol dependence is independent of gender and is estimated to range from 40 to $70 \%$ based on twin and adoption studies [10, 48]. Most of the genes and their polymorphisms that have been linked to alcohol dependence both in a predisposing as well as a protective way are related to alcohol metabolism and neurotransmission $[7,46]$.

In this study, the genetic susceptibility to harmful alcohol consumption in Hungarian psoriasis patients was compared to subjects of general population, by analyzing and comparing the frequencies of 23 alleles associated with alcohol consumption behaviors based on literature review and recent publication [7]. We aimed to address if genetic factors driving alcohol consumption could be linked to psoriasis, or whether primarily environmental factors contribute to the increased alcohol consumption of psoriatic patients [9].

\section{Materials and methods}

\section{Study population and characteristics}

A total of 776 patients (580 patients from Debrecen region and 196 patients from Budapest region) diagnosed with psoriasis vulgaris and 2967 individuals from the Hungarian general population (HG) were enrolled in the study.

The diagnosis of psoriasis was approved by at least two dermatologists. Data including family history (familial aggregation was positive if psoriasis existed in at least one more case among first degree relatives extended with grandparents in familial anamnestic data) and age at onset (early onset: $\leq 40$ years, late onset $>40$ years) were collected and their association with HLA-Cw*0602 allele was defined. To assess the severity of psoriasis Psoriasis Area and Severity Index (PASI) score was used. Symptoms were dichotomized as follows: in case of patients receiving only topical treatment and/or PASI $<10$ without therapy was specified as mild psoriasis, $\geq 10$ as severe psoriasis. Patients receiving systemic therapy were all included in the severe psoriasis group independent of the recent PASI score.

Sample representative of the HG population in terms of geographic, age and sex distributions were obtained from a population-based disease registry, the General Practitioners' Morbidity Sentinel Stations Programme (GPMSSP) [43].
Our study involved HG subjects investigated during a recent cross-sectional survey. Details of sampling methodology and data collection are described elsewhere [44].

Informed consent was obtained from all individual participants included in the study. The study protocol was approved by the Regional Institutional Scientific and Research Ethical Board of the University of Debrecen and by the Semmelweis University, Budapest, Hungary in accordance with the principles from the Declaration of Helsinki.

\section{SNP selection}

A recent study conducted systematic literature review (PubMed) to identify SNPs of candidate genes most likely to be associated with the characteristics of alcohol consumption by encoding enzymes involved in alcohol metabolism and in pathways related to dependence [7]. Our study utilized the same collection set: alcohol dehydrogenase $(A D H 1 B$, $A D H 1 C$ ), aldehyde dehydrogenase (ALDH1A1, ALDH2) and neurotransmitters in the dopaminergic (SLC6A3, $D D C)$, GABAergic (GABRA2, GABRG1), serotonergic (HTR1B, MAOA, TPH2), cholinergic (CHRM2), glutamatergic (GRIN2A) and opioidergic (POMC, OPRM1, OPRK1) pathways, as well as one SNP in the gene encoding a protein involved in neural development and dendritic growth neurogenesis $(B D N F)$ (Supplementary Table 1).

\section{DNA preparation}

DNA isolation was performed from ethylenediaminetetraacetic acid-anticoagulated blood samples using the MagNA Pure LC DNA Isolation Kit—Large Volume (Roche Diagnostics, Mannheim, Germany) according to the manufacturer's protocol. The extracted DNA samples were eluted in MagNA Pure LC DNA Isolation Kit-Large Volume Elution Buffer (Roche Diagnostics) and stored in $-30{ }^{\circ} \mathrm{C}$ until measurements.

\section{Genotype assessment}

Genotyping of the selected 23 SNPs was performed by Mutation Analysis Core Facility (MAF) of Clinical Research Center, Karolinska University Hospital (Stockholm, Sweden) using the Mass Array platform with iPLEX Gold Chemistry (Sequenom). The validation, concordance analysis and quality control were conducted by MAF according to their protocol, resulting in a successful genotyping outcome for 3433 (776 psoriatic and 2917 HG) DNA samples. HLA$\mathrm{CW}^{*} 0602$ typing was carried out as described previously [34]. 


\section{Statistical analyses}

The data were analyzed using STATA 12.0 Statistical software (StataCorp LP, College Station, TX, USA). The Mann-Whitney $U$ and $\chi^{2}$ tests were used to compare the mean age and sex distribution of the two study groups. The existence of Hardy-Weinberg equilibrium (HWE) and significant differences in the allele and genotype frequencies between the two populations were examined with the $\chi^{2}$ test. To decrease the proportion of false positive results the $p$ threshold of 0.002 was applied (Bonferroni correction); otherwise the threshold for significance was 0.05 .

To take account of confounding effects of gender and age on differences between study populations, linear regression models were constructed. Psoriatic samples were divided into several subgroups defined by the clinical parameters such as familial aggregation, age at onset, and severity as described previously. Association analyses were done according to additive, dominant and recessive models. To further confirm the findings two psoriatic populations from Hungary (Budapest vs. Debrecen) were also compared.

To assess whether any allele frequency differences exist between the Debrecen and the Budapest subgroups of the patients $\chi^{2}$ tests were performed. Similar genotype distribution of the SNPs were found in these subgroups, suggesting that the association of psoriasis with the identified risk alleles in the Hungarian psoriatic patients, is independent of the regional origin of the patients.

To assess gene-gene interactions between HLA-Cw*0602 and the ADH1B and OPRM1 genes PLINK software epistasis command was used [38].

\section{Results}

\section{Comparison of psoriasis population to Hungarian general population}

The mean age was 49.15 years \pm 16.82 in the case of psoriatic patients and 45.53 years \pm 14.62 in the case of the HG population. The mean age of the study groups was significantly different according to the Mann-Whitney $U$ test $(p<0.001)$. The proportion of male individuals in psoriatic sample was significantly higher (psoriatic: $60.6 \%$ vs. HG: $46.8 \%, p<0.001)$.

Out of the 23 SNPs investigated, the genotype distribution of rs 1386496 (TPH2 gene) deviated from Hardy-Weinberg equilibrium in the HG group $(p<0.001)$ and was thus excluded from further analysis. Allele frequencies in the study populations, which were calculated on the basis of the obtained genotype distributions, are shown in Table 1. $A L D H 2$ rs671 and $S L C 6 A 3$ rs6530 were monomorphic in both groups, and were consequently excluded from further analyses.

Differences between the psoriatic and HG population remained significant only for one SNP (rs1229984) after multiple test correction. Comparing the allele frequency distribution of SNP rs1229984 in the gene coding alcohol dehydrogenase $1 \mathrm{~B}(A D H 1 B)$ significantly higher prevalence of effect allele $\mathrm{C}$ was found in the psoriatic population compared to the HG population ( $94.46 \%$ vs. $92.04 \%, p<0.001$, respectively). Significant differences were observed between study groups in the association analysis according to the additive $\left(\mathrm{OR}_{\text {additive }}=1.58,95 \% \mathrm{CI} 1.23-2.03, p<0.001\right)$ and the recessive model $\left(\mathrm{OR}_{\text {recessive }}=1.58,95 \%\right.$ CI 1.22-2.04, $p=0.001)$ but not the dominant model $\left(\mathrm{OR}_{\mathrm{dominant}}=4.29\right.$, 95\% CI 0.55-33.08, $p=0.163$ ) (Table 1).

\section{Stratified analysis of psoriasis group}

By comparing the psoriasis subgroups several strata of psoriatic patients were defined, such as familial aggregation vs. sporadic case, early-onset of disease ( $\leq 40$ years) vs. lateonset $(>40$ years) and mild (PASI score $<10)$ vs. severe psoriasis symptoms (PASI score $\geq 10$ or receiving systemic therapy). The number of psoriatic subjects in the subgroup analysis (Supplementary Table 2) were sufficient to attain power of $80 \%$ and to detect an OR of 1.9 (assuming at least case-control ratio of 1.8 and alfa $=0.05)$. The statistical power was calculated using Epiinfo 7.2 StatCalc calculator.

Significant results were found only in case of one SNP, rs1799971 ( $\mu$-opioid receptor gene, OPRM1) when familial cases were compared to sporadic cases, The effect allele $\mathrm{G}$ increased the risk of familial psoriasis by twofold compared to sporadic cases both in additive and in dominant models $\left(\mathrm{OR}_{\text {additive }}=1.99,95 \%\right.$ CI 1.36-2.91, $p<0.001$, $\mathrm{OR}_{\text {dominant }}=2.01,95 \%$ CI 1.35-3.01, $\left.p<0.001\right)($ Table 2),

When creating an additional subgroup from psoriatic patients with history of early onset ( $\leq 40$ years) and familial aggregation and comparing it to the HG population, in case of the rs1229984 (ADH1B) and rs1799971 (OPRM1) significant associations were found. The effect allele ' $\mathrm{C}$ ' (rs1229984) both in the additive and recessive models, increased the risk of psoriasis similarly to the finding represented in Table 1 . However, in the subgroup analysis the $\mathrm{OR}$ was much larger $\left(\mathrm{OR}_{\text {additive }}=2.41\right.$, 95\% CI 1.26-4.61, $p<0.01, \mathrm{OR}_{\text {recessive }}=2.42,95 \% \mathrm{CI}$ $1.26-4.68, p<0.01$, Table 3). Furthermore, the $\mathrm{G}$ allele of the rs1799971 (OPRM1) was also significantly associated with increased psoriasis risk in the additive and dominant models $\left(\mathrm{OR}_{\text {additive }}=1.75,95 \%\right.$ CI 1.27-2.43, $p=0.001$, $\mathrm{OR}_{\text {dominant }}=1.82,95 \%$ CI 1.26-2.63, $\left.p=0.001\right)($ Table 3$)$.

Familial aggregation and early onset of psoriasis inevitably suggest the involvement of genetic factors and is highly associated with HLA-Cw*0602. In our cohort, psoriatic patients 
Table 1 Effect allele frequency distribution of the investigated SNPs

\begin{tabular}{|c|c|c|c|c|c|c|c|c|}
\hline Gene & SNP & Effect allele & $\begin{array}{l}\text { Effect allele frequency } \\
\text { among psoriasis patients, } \\
N=776\end{array}$ & $\begin{array}{l}\text { Effect allele frequency } \\
\text { in general population, } \\
N=2967\end{array}$ & $p$ & Model & OR $(95 \% \mathrm{CI})$ & $p$ \\
\hline \multirow[t]{3}{*}{ POMCs } & rs 1866146 & G & 0.3807 & 0.3955 & 0.299 & ADD & $0.94(0.83-1.06)$ & 0.3295 \\
\hline & & & & & & DOM & $0.85(0.72-1.01)$ & 0.059 \\
\hline & & & & & & REC & $1.08(0.86-1.36)$ & 0.505 \\
\hline \multirow[t]{3}{*}{ POMC } & rs6713532 & $\mathrm{C}$ & 0.2627 & 0.2619 & 0.951 & ADD & $0.999(0.87-1.14)$ & 0.9885 \\
\hline & & & & & & DOM & $1.06(0.89-1.25)$ & 0.518 \\
\hline & & & & & & REC & $0.79(0.55-1.12)$ & 0.185 \\
\hline \multirow[t]{3}{*}{ GABRG1 } & rs2221020 & $\mathrm{C}$ & 0.5183 & 0.5176 & 0.958 & ADD & $0.99(0.89-1.12)$ & 0.9233 \\
\hline & & & & & & DOM & $0.94(0.78-1.14)$ & 0.525 \\
\hline & & & & & & REC & $1.04(0.87-1.25)$ & 0.652 \\
\hline \multirow[t]{3}{*}{ GABRA2 } & rs567926 & G & 0.3997 & 0.3954 & 0.762 & ADD & $1.01(0.90-1.14)$ & 0.8607 \\
\hline & & & & & & DOM & $1.05(0.88-1.25)$ & 0.5801 \\
\hline & & & & & & REC & $0.96(0.76-1.2)$ & 0.694 \\
\hline \multirow[t]{3}{*}{ GABRA2 } & rs279871 & $\mathrm{T}$ & 0.6112 & 0.6126 & 0.92 & $\mathrm{ADD}$ & $0.99(0.88-1.12)$ & 0.9327 \\
\hline & & & & & & DOM & $1.13(0.89-1.43)$ & 0.3079 \\
\hline & & & & & & REC & $0.93(0.78-1.10)$ & 0.3799 \\
\hline \multirow[t]{3}{*}{ GABRA2 } & rs279858 & $\mathrm{C}$ & 0.3914 & 0.3869 & 0.751 & $\mathrm{ADD}$ & $1.02(0.90-1.15)$ & 0.7629 \\
\hline & & & & & & DOM & $1.11(0.93-1.31)$ & 0.2532 \\
\hline & & & & & & REC & $0.89(0.71-1.13)$ & 0.3399 \\
\hline \multirow[t]{3}{*}{ ADH5 } & rs 1154400 & $\mathrm{C}$ & 0.3377 & 0.3405 & 0.843 & ADD & $0.97(0.86-1.10)$ & 0.6861 \\
\hline & & & & & & DOM & $0.98(0.83-1.17)$ & 0.8557 \\
\hline & & & & & & REC & $0.93(0.71-1.21)$ & 0.573 \\
\hline \multirow[t]{3}{*}{ ADH4 } & rs7694646 & A & 0.3191 & 0.3043 & 0.272 & ADD & $1.07(0.94-1.21)$ & 0.3234 \\
\hline & & & & & & DOM & $1.06(0.90-1.25)$ & 0.5137 \\
\hline & & & & & & REC & $1.06(0.89-1.53)$ & 0.278 \\
\hline \multirow[t]{3}{*}{ ADH4 } & rs1800759 & G & 0.5885 & 0.5932 & 0.746 & ADD & $0.9991(0.89-1.13)$ & 0.9888 \\
\hline & & & & & & DOM & $0.86(0.69-1.07)$ & 0.1691 \\
\hline & & & & & & REC & $1.098(0.92-1.30)$ & 0.2906 \\
\hline \multirow[t]{3}{*}{ ADH1B } & rs1229984 & $\mathrm{C}$ & 0.946 & 0.9204 & 0.001 & $\mathrm{ADD}$ & $1.58(1.23-2.03)$ & 0.000371 \\
\hline & & & & & & DOM & $4.29(0.55-33.08)$ & 0.163 \\
\hline & & & & & & REC & $1.58(1.22-2.04)$ & 0.001 \\
\hline \multirow[t]{3}{*}{ ADH7 } & rs1154458 & $\mathrm{C}$ & 0.4207 & 0.412 & 0.543 & ADD & $1.06(0.95-1.20)$ & 0.3015 \\
\hline & & & & & & DOM & $1.05(0.88-1.25)$ & 0.5672 \\
\hline & & & & & & REC & $1.14(0.92-1.41)$ & 0.2906 \\
\hline \multirow[t]{3}{*}{ SLC6A3 } & rs463379 & G & 0.7849 & 0.7746 & 0.396 & $\mathrm{ADD}$ & $1.05(0.91-1.21)$ & 0.5035 \\
\hline & & & & & & DOM & $1.56(1.01-2.40)$ & 0.04589 \\
\hline & & & & & & REC & $0.99(0.84-1.18)$ & 0.9367 \\
\hline \multirow[t]{3}{*}{ HTR1B } & rs 130058 & $\mathrm{~T}$ & 0.7167 & 0.7234 & 0.608 & ADD & $0.96(0.85-1.10)$ & 0.582 \\
\hline & & & & & & DOM & $1.08(0.79-1.47)$ & 0.631 \\
\hline & & & & & & REC & $0.92(0.78-1.09)$ & 0.3355 \\
\hline \multirow[t]{3}{*}{ OPRM1 } & rs1799971 & G & 0.132 & 0.1311 & 0.927 & ADD & $0.99(0.83-1.18)$ & 0.8785 \\
\hline & & & & & & DOM & $1.01(0.83-1.22)$ & 0.9315 \\
\hline & & & & & & REC & $0.69(0.31-1.51)$ & 0.3493 \\
\hline \multirow[t]{3}{*}{ DDC } & rs3779084 & G & 0.21 & 0.2019 & 0.487 & $\mathrm{ADD}$ & $1.06(0.93-1.21)$ & 0.37 \\
\hline & & & & & & DOM & $1.05(0.88-1.25)$ & 0.6003 \\
\hline & & & & & & REC & $1.2(0.89-1.60)$ & 0.2352 \\
\hline \multirow[t]{3}{*}{ CHRM2 } & rs 324650 & A & 0.5026 & 0.5117 & 0.531 & ADD & $0.96(0.85-1.08)$ & 0.4842 \\
\hline & & & & & & DOM & $0.94(0.78-1.14)$ & 0.5233 \\
\hline & & & & & & REC & $0.95(0.79-1.15)$ & 0.6137 \\
\hline
\end{tabular}


Table 1 (continued)

\begin{tabular}{|c|c|c|c|c|c|c|c|c|}
\hline Gene & SNP & Effect allele & $\begin{array}{l}\text { Effect allele frequency } \\
\text { among psoriasis patients, } \\
N=776\end{array}$ & $\begin{array}{l}\text { Effect allele frequency } \\
\text { in general population, } \\
N=2967\end{array}$ & $p$ & Model & OR $(95 \% \mathrm{CI})$ & $p$ \\
\hline \multirow[t]{3}{*}{ OPRK1 } & rs6985606 & $\mathrm{T}$ & 0.4735 & 0.4734 & 0.994 & ADD & $1.004(0.89-1.13)$ & 0.9522 \\
\hline & & & & & & DOM & $1.01(0.84-1.22)$ & 0.8812 \\
\hline & & & & & & REC & $0.99(0.81-1.21)$ & 0.9533 \\
\hline \multirow[t]{3}{*}{ ALDH1A1 } & rs610529 & $\mathrm{G}$ & 0.4397 & 0.4467 & 0.63 & $\mathrm{ADD}$ & $0.980 .87-1.10)$ & 0.7383 \\
\hline & & & & & & DOM & $1.05(0.88-1.26)$ & 0.6057 \\
\hline & & & & & & REC & $0.88(0.71-1.09)$ & 0.2373 \\
\hline \multirow[t]{3}{*}{ BDNF } & rs6265 & $\mathrm{C}$ & 0.8197 & 0.8003 & 0.093 & $\mathrm{ADD}$ & $1.15(0.98-1.33)$ & 0.08108 \\
\hline & & & & & & DOM & $1.27(0.79-2.05)$ & 0.3276 \\
\hline & & & & & & REC & $1.16(0.97-1.38)$ & 0.09954 \\
\hline \multirow[t]{3}{*}{ GRIN2A } & rs2072450 & $\mathrm{C}$ & 0.8687 & 0.8641 & 0.646 & ADD & $1.17(0.90-1.27)$ & 0.443 \\
\hline & & & & & & DOM & $1.3(0.69-2.42)$ & 0.4179 \\
\hline & & & & & & REC & $1.06(0.87-1.29)$ & 0.549 \\
\hline \multirow[t]{3}{*}{ MAOA } & rs979606 & $\mathrm{T}$ & 0.6849 & 0.6832 & 0.916 & ADD & $1.013(0.873-1.176)$ & 0.862 \\
\hline & & & & & & DOM & $\mathrm{NA}^{\mathrm{a}}$ & $\mathrm{NA}^{\mathrm{a}}$ \\
\hline & & & & & & REC & $\mathrm{NA}^{\mathrm{a}}$ & $\mathrm{NA}^{\mathrm{a}}$ \\
\hline
\end{tabular}

Multiple test correction revealed significant differences for rs 1229984 ( $A D H 1 B$ ) between the psoriatic and HG population

${ }^{a} N A$ not applicable, rs979606 was X-linked

Table 2 Association of rs1799971 with psoriasis vulgaris analysed by subgroups (onset, familial vs. sporadic and severity)

\begin{tabular}{|c|c|c|c|c|c|c|}
\hline \multirow[t]{2}{*}{ Phenotype groups } & Additive (GG vs. AA) & $p$ value & $\begin{array}{l}\text { Recessive (GG } \\
\text { vs. GA + AA) }\end{array}$ & $p$ value & $\begin{array}{l}\text { Dominant } \\
\text { (GG + GA vs. } \\
\text { AA) }\end{array}$ & $p$ value \\
\hline & OR $(95 \% \mathrm{CI})$ & & OR $(95 \% \mathrm{CI})$ & & OR $(95 \% \mathrm{CI})$ & \\
\hline $\begin{array}{l}\text { Early-onset psoriasis ( } \leq 40 \text { years) vs. late -onset ( }>40 \\
\text { years) }\end{array}$ & $0.66(0.44-1.01)$ & 0.054 & $1.17(0.17-7.85)$ & 0.871 & $0.62(0.39-0.97)$ & 0.035 \\
\hline Familial psoriasis vs. sporadic psoriasis & $1.99(1.36-2.91)$ & 0.0003 & $4.53(0.77-26.4)$ & 0.092 & $2.01(1.35-3.01)$ & 0.0006 \\
\hline $\begin{array}{l}\text { Severe psoriasis }(\mathrm{PASI} \geq 10) \text { vs. mild psoriasis } \\
\quad(\mathrm{PASI}<10)\end{array}$ & $0.97(0.65-1.45)$ & 0.900 & $0.79(0.13-4.85)$ & 0.808 & $1.05(0.68-1.59)$ & 0.829 \\
\hline
\end{tabular}

Significant results for rs1799971 (OPRM1) were found when familial cases were compared to sporadic cases (highlighted in bold)

Table 3 Associations of rs1799971 and rs1229984 in case of additional psoriasis vulgaris subgroups (history of early onset ( $\leq 40$ years) and familial aggregation) compared to the general population

\begin{tabular}{|c|c|c|c|c|c|c|c|c|}
\hline \multirow[t]{2}{*}{ SNP } & \multirow[t]{2}{*}{ Effect alelle } & \multirow[t]{2}{*}{$\begin{array}{l}\text { Phenotype groups vs. } \\
\text { HG }\end{array}$} & $\begin{array}{l}\text { Additive (GG/CC vs. } \\
\text { AA) }\end{array}$ & \multirow[t]{2}{*}{$p$ value } & $\begin{array}{l}\text { Recessive (GG/ } \\
\text { CC vs. GA/ } \\
\text { CA + AA) }\end{array}$ & \multirow[t]{2}{*}{$p$ value } & $\begin{array}{l}\text { Dominant }(\mathrm{GG} / \\
\mathrm{CC}+\mathrm{GA} / \mathrm{CA} \text { vs. } \\
\mathrm{AA})\end{array}$ & \multirow[t]{2}{*}{$p$ value } \\
\hline & & & OR $(95 \% \mathrm{CI})$ & & OR (95\% CI) & & OR (95\% CI) & \\
\hline rs1799971 & G & $\begin{array}{c}\text { Early-onset ( } \leq 40 \text { years) } \\
\quad+\text { familial aggregation } \\
\text { vs. general population }\end{array}$ & $1.75(1.27-2.43)$ & 0.001 & $2.57(0.87-7.62)$ & 0.088 & $1.82(1.26-2.63)$ & 0.001 \\
\hline rs 1229984 & $\mathrm{C}$ & $\begin{array}{l}\text { Early-onset ( } \leq 40 \text { years) } \\
\quad+\text { familial aggregation } \\
\text { vs. general population }\end{array}$ & $2.41(1.26-4.61)$ & 0.008 & $2.42(1.26-4.68)$ & 0.008 & $1.08(0.1-2.3)$ & 0.998 \\
\hline
\end{tabular}

In case of rs1229984 (ADH1B) and rs1799971 (OPRM1) significant associations were found when the subgroup from psoriatic patients with history of early onset ( $\leq 40$ years) and familial aggregation was compared to the HG population (highlighted in bold) 
who had a history of familial aggregation, the risk allele of HLA-Cw*0602 gene occurred more frequently compared to patients having sporadic disease $(53.80 \%$ vs. $34.78 \%$, $p<0.001$, respectively), while among patients who had early-onset disease the proportion of those having at least one HLA-Cw*0602 risk allele was higher compared to those who had late onset disease ( $47.99 \%$ vs $28.08 \%, p<0.001$, respectively) (Supplementary Table 3). However, neither rs1229984 (ADH1B) nor rs1799971 (OPRM1) showed a significant association when subgroups formed on the presence of at least one HLA-Cw*0602 allele were compared. Assessing a possible gene-gene interaction between HLA-Cw*0602 and the ADH1B and OPRM1 genes in the early-onset vs. late-onset and familial aggregation vs. sporadic subgroups of patients no evidence on epistasis was found in any of the subgroups.

Furthermore, there were no differences in the risk allele distribution among HLA-Cw*0602 positive men and women in case of any SNPs.

\section{Discussion}

The association between psoriasis and increased alcohol consumption has been reported in several studies, including the conclusion that alcohol consumption or abuse is an independent risk factor for the development of the disease. However, whether this association is driven by genetic factors has not been answered yet and therefore, in this study we evaluated the relationship between 23 SNPs related to increased alcohol intake and dependence in a Hungarian psoriasis group. We found that the frequency of the genetic variant rs1229984 (ADH1B) increased in the whole psoriasis group, while genetic variant rs1799971 (OPRM1) showed higher prevalence in the familial form of psoriasis patients. Importantly, the risk of psoriasis related to these variants increased further in the subgroup of psoriatic patients with history of early onset and familial aggregation, but with no association to the HLA-Cw*0602 allele.

Keeping the limitations in mind, it is intriguing to speculate on how the detected SNPs, which are primarily related to affecting the behaviour of an individual, may be involved also in the pathogenesis of psoriasis.

ADH1B is a key enzyme in the metabolism of ethanol to acetaldehyde and subsequent oxidation to acetate. The allele $\mathrm{G}$ which was increased in the psoriasis population leads to an increased enzyme activity, thus to decreased levels of the harmful acetaldehyde following alcohol ingestion. In contrast, the protective allele is linked to a high blood acetaldehyde concentration, which is accounted to make drinking unpleasant, and is behind the "Oriental flushing response" characterized by facial flushing, headache, tachycardia, and nausea $[19,30]$. These symptoms altogether are considered to be a genetic deterrent to heavy drinking and alcoholism among East-Asians, where the predisposing alleles in rs 1229984 of $A D H 1 B$ is around $10 \%$ in contrast to the $90 \%$ found in the Hungarian and European populations [26]. Importantly, ADH1B is expressed not just in the liver where the majority of the alcohol metabolism takes place, but in the skin as well [5]. Moreover, its metabolite acetaldehyde, was found to induce the proliferation [14] and the production of pro-inflammatory cytokines in keratinocytes under in vitro conditions, that could provide a missing piece in the puzzle of how alcohol could increase the severity of psoriasis. Based on these data, further studies could reveal important keratinocyte specific differences in the allele carrying patients. Another interesting aspect for further investigations is that ADH1B is most likely capable of metabolizing retinoic acid as well which could account for an altered response of psoriatic patients to retinoic acid based therapies [29].

OPRM1 encodes the $\mu$-opioid receptor, which upon activation by its ligands, such as opioids and analgesic agents such as beta-endorphin, modulates the dopamine system [22]. It is implicated in complex behavior patterns such as alcohol dependence in Caucasian, native American tribes as well as in a study group of Asian descends [4, 8, $23,24]$ in alcohol dependence associated impulsivity [35] just as in a reduced response to rewarding stimuli [25, 39]. Out of the alleles, $118 \mathrm{G}$ has the major susceptibility effect. In individuals carrying $118 \mathrm{G}$ stimulation, sedation, and positive mood levels after alcohol intake were significantly higher than in controls [39]. These effects are confirmed in great by studies on its antagonist, naltrexone, which is prescribed to alcohol dependent people to help them reduce cravings, control or abstain from drinking [28]. However, there are also studies that did not find a higher risk for alcohol dependence among OPRM1 118G-allele carriers, just as there are alcohol dependent patients who do not observe the beneficial effects of naltrexone [1, 16, 42]. Thus, patient characteristics and the genetic/environmental settings that modulate the OPRM1 related behavior needs to be defined in more details. Regarding psoriasis, there is a significant amount of data on the impact of psoriasis on health behavior by causing psychological stress and psychosocial disability [15]. However, how neurotransmitters are involved in the observed changes and could integrate into the psoriasis skin-brain axis has been addressed only in limited details [21, 40]. Importantly, opioid receptors, besides the CNS, are also expressed in the epidermis ( $\mu$ and $\kappa$ isoforms) with a possible role in transmitting the sensation of itch. While activation of $\mu$-opioid receptors induces pruritus, activation of $\kappa$-opioid receptors is suggested to have a suppressive effect [2]. Moreover, the $\kappa$-opioid, but not the $\mu$-opioid receptor was down-regulated in psoriasis skin [47]. These results altogether put forward the question how itch is affecting the alcohol use of psoriasis patients and how the detected risk allele of OPRMI 
could contribute. Our results, therefore, open new perspectives to stratify psoriasis subgroups also based on itch and alcohol use [51]. Moreover, the association between psoriasis and the opiate signaling pathway, provides excellent start points for further studies on understanding not just psoriasis associated stress and related risk behavior but also to identify psychiatric disorders that may be linked to psoriasis or at least to subsets of psoriatic patients on the level of genetic association [41].

A limitation of this study is that although both SNPs were confirmed to be significant in our two independent Hungarian study subgroups, their prevalence did not reach significance values in a psoriasis cohort [33] from Sweden. Therefore, these findings call for further studies to map these SNPs in a geographic distribution. While, to draw conclusions on the functional relevance of the identified SNPs regarding the behavior, and perhaps the symptoms and the response to specific therapies such as topical $\mu$-opioid receptor antagonists [45] in a subgroup of psoriatic patients with itch, a larger sample size is needed than what we used for this study.

In conclusion, our data suggests that genetically defined high-risk individuals for alcohol consumption are more common among psoriasis patients in the general population in Hungary, which calls for further studies on how genetic determinants of health behavior could be integrated into the psoriasis-psychic stress-alcohol consumption cycle, just as into psoriasis management.

Acknowledgments Open access funding provided by University of Debrecen (DE).

Funding This research was supported by TÁMOP-4.2.2.A-11/1/KONV2012-0031 IGEN Hungarian Project and by GINOP-2.3.2-2016-00005 which are co-financed by the European Union and the European Social Fund. DT is a recipient of the Janos Bolyai research scholarship of the Hungarian Academy of Sciences, supported by the UNKP-18-4 New National Excellence Program of the Ministry of Human Capacities and by the Marie Skłodowska-Curie actions (627547 FP7-PEOPLE2013-IEF). The funders had no role in study design, data collection and analysis, decision to publish, or preparation of the manuscript.

\section{Compliance with ethical standards}

Conflicts of interest The authors declare that they have no conflict of interest.

Statement of human rights All procedures performed in studies involving human participants were in accordance with the ethical standards of the institutional and/or national research committee and with the 1964 Helsinki declaration and its later amendments or comparable ethical standards.

Informed consent Written informed consent was obtained from all participants. The study protocol was approved by the Regional Institutional Scientific and Research Ethical Board of the University of Debrecen and by the Semmelweis University, Budapest, Hungary in accordance with the principles from the Declaration of Helsinki.
Open Access This article is distributed under the terms of the Creative Commons Attribution 4.0 International License (http://creativeco mmons.org/licenses/by/4.0/), which permits unrestricted use, distribution, and reproduction in any medium, provided you give appropriate credit to the original author(s) and the source, provide a link to the Creative Commons license, and indicate if changes were made.

\section{References}

1. Bergen AW, Kokoszka J, Peterson R, Long JC, Virkkunen M, Linnoila M, Goldman D (1997) Mu opioid receptor gene variants: lack of association with alcohol dependence. Mol Psychiatry. 2:490-494

2. Bigliardi PL, Tobin DJ, Gaveriaux-Ruff C, Bigliardi-Qi M (2009) Opioids and the skin-where do we stand? Exp Dermatol $18: 424-430$

3. Brenaut E, Horreau C, Pouplard C, Barnetche T, Paul C, Richard MA, Joly P, Le Maitre M, Aractingi S, Aubin F, Cribier B, Jullien D, Ortonne JP, Misery L (2013) Alcohol consumption and psoriasis: a systematic literature review. J Eur Acad Dermatol Venereol 27(Suppl 3):30-35

4. Chen D, Liu L, Xiao Y, Peng Y, Yang C, Wang Z (2012) Ethnicspecific meta-analyses of association between the oprm 1 a1 $18 \mathrm{~g}$ polymorphism and alcohol dependence among asians and caucasians. Drug Alcohol Depend 123:1-6

5. Cheung C, Smith CK, Hoog JO, Hotchkiss SA (1999) Expression and localization of human alcohol and aldehyde dehydrogenase enzymes in skin. Biochem Biophys Res Commun 261:100-107

6. Dika E, Bardazzi F, Balestri R, Maibach HI (2007) Environmental factors and psoriasis. Curr Probl Dermatol 35:118-135

7. Dioszegi J, Fiatal S, Toth R, Moravcsik-Kornyicki A, Kosa Z, Sandor J, McKee M, Adany R (2017) Distribution characteristics and combined effect of polymorphisms affecting alcohol consumption behaviour in the hungarian general and roma populations. Alcohol Alcohol 52:104-111

8. Ehlers CL, Gizer IR (2013) Evidence for a genetic component for substance dependence in native americans. Am J Psychiatry 170:154-164

9. Eissing L, Radtke MA, Zander N, Augustin M (2016) Barriers to guideline-compliant psoriasis care: analyses and concepts. J Eur Acad Dermatol Venereol 30:569-575

10. Enoch MA, Goldman D (2001) The genetics of alcoholism and alcohol abuse. Curr Psychiatry Rep 3:144-151

11. Eskin M, Savk E, Uslu M, Kucukaydogan N (2014) Social problem-solving, perceived stress, negative life events, depression and life satisfaction in psoriasis. J Eur Acad Dermatol Venereol 28:1553-1559

12. Farkas A, Kemeny L (2010) The alcohol metabolite acetaldehyde and psoriasis: another trigger factor? Clin Exp Dermatol 35:923-925

13. Farkas A, Kemeny L (2010) Psoriasis and alcohol: is cutaneous ethanol one of the missing links? Br J Dermatol 162:711-716

14. Farkas A, Kemeny L (2013) Alcohol, liver, systemic inflammation and skin: a focus on patients with psoriasis. Skin Pharmacol Physiol 26:119-126

15. Fortune DG, Main CJ, O'Sullivan TM, Griffiths CE (1997) Quality of life in patients with psoriasis: the contribution of clinical variables and psoriasis-specific stress. Br J Dermatol 137:755-760

16. Franke P, Wang T, Nothen MM, Knapp M, Neidt H, Albrecht S, Jahnes E, Propping P, Maier W (2001) Nonreplication of association between mu-opioid-receptor gene (oprm1) a118 g 
polymorphism and substance dependence. Am J Med Genet 105:114-119

17. Gerdes S, Zahl VA, Weichenthal M, Mrowietz U (2010) Smoking and alcohol intake in severely affected patients with psoriasis in germany. Dermatology 220:38-43

18. Gupta MA, Schork NJ, Gupta AK, Ellis CN (1993) Alcohol intake and treatment responsiveness of psoriasis: a prospective study. J Am Acad Dermatol 28:730-732

19. Harada S, Agarwal DP, Goedde HW (1981) Aldehyde dehydrogenase deficiency as cause of facial flushing reaction to alcohol in japanese. Lancet 2:982

20. Higgins EM, du Vivier AW (1992) Alcohol and the skin. Alcohol Alcohol 27:595-602

21. Hunter HJ, Griffiths CE, Kleyn CE (2013) Does psychosocial stress play a role in the exacerbation of psoriasis? Br J Dermatol 169:965-974

22. Johnson SW, North RA (1992) Opioids excite dopamine neurons by hyperpolarization of local interneurons. J Neurosci 12:483-488

23. Koller G, Zill P, Rujescu D, Ridinger M, Pogarell O, Fehr C, Wodarz N, Bondy B, Soyka M, Preuss UW (2012) Possible association between oprm 1 genetic variance at the 118 locus and alcohol dependence in a large treatment sample: relationship to alcohol dependence symptoms. Alcohol Clin Exp Res 36:1230-1236

24. Kranzler HR, Gelernter J, O'Malley S, Hernandez-Avila CA, Kaufman D (1998) Association of alcohol or other drug dependence with alleles of the mu opioid receptor gene (oprm1). Alcohol Clin Exp Res 22:1359-1362

25. Lee MR, Gallen CL, Zhang X, Hodgkinson CA, Goldman D, Stein EA, Barr CS (2011) Functional polymorphism of the muopioid receptor gene (oprm1) influences reinforcement learning in humans. PLoS One 6:e24203

26. Li H, Mukherjee N, Soundararajan U, Tarnok Z, Barta C, Khaliq S, Mohyuddin A, Kajuna SL, Mehdi SQ, Kidd JR, Kidd KK (2007) Geographically separate increases in the frequency of the derived adh $1 \mathrm{~b} * 47$ his allele in eastern and western asia. Am J Hum Genet 81:842-846

27. McAleer MA, Mason DL, Cunningham S, O'Shea SJ, McCormick PA, Stone C, Collins P, Rogers S, Kirby B (2011) Alcohol misuse in patients with psoriasis: identification and relationship to disease severity and psychological distress. Br J Dermatol 164:1256-1261

28. Mitchell JM, Tavares VC, Fields HL, D'Esposito M, Boettiger CA (2007) Endogenous opioid blockade and impulsive responding in alcoholics and healthy controls. Neuropsychopharmacology. 32:439-449

29. Molotkov A, Deltour L, Foglio MH, Cuenca AE, Duester G (2002) Distinct retinoid metabolic functions for alcohol dehydrogenase genes adh 1 and adh 4 in protection against vitamin a toxicity or deficiency revealed in double null mutant mice. J Biol Chem 277:13804-13811

30. Muramatsu T, Wang ZC, Fang YR, Hu KB, Yan H, Yamada K, Higuchi S, Harada S, Kono H (1995) Alcohol and aldehyde dehydrogenase genotypes and drinking behavior of chinese living in shanghai. Hum Genet 96:151-154

31. Nair RP, Stuart P, Henseler T, Jenisch S, Chia NV, Westphal E, Schork NJ, Kim J, Lim HW, Christophers E, Voorhees JJ, Elder JT (2000) Localization of psoriasis-susceptibility locus psors1 to a 60-kb interval telomeric to hla-c. Am J Hum Genet 66:1833-1844

32. Nestle FO, Kaplan DH, Barker J (2009) Psoriasis. N Engl J Med 361:496-509

33. Nikamo P, Lysell J, Stahle M (2015) Association with genetic variants in the il-23 and nf-kappab pathways discriminates between mild and severe psoriasis skin disease. J Invest Dermatol 135:1969-1976

34. Nikamo P, Stahle M (2012) Cost-effective hla-cw06:02 typing in a caucasian population. Exp Dermatol 21:221-223
35. Pfeifer P, Sariyar M, Eggermann T, Zerres K, Vernaleken I, Tuscher O, Fehr C (2015) Alcohol consumption in healthy oprm1 $\mathrm{g}$ allele carriers and its association with impulsive behavior. Alcohol Alcohol 50:379-384

36. Poikolainen K, Reunala T, Karvonen J (1994) Smoking, alcohol and life events related to psoriasis among women. Br J Dermatol 130:473-477

37. Poikolainen K, Reunala T, Karvonen J, Lauharanta J, Karkkainen P (1990) Alcohol intake: a risk factor for psoriasis in young and middle aged men? BMJ 300:780-783

38. Purcell S, Neale B, Todd-Brown K, Thomas L, Ferreira MA, Bender D, Maller J, Sklar P, de Bakker PI, Daly MJ, Sham PC (2007) Plink: a tool set for whole-genome association and population-based linkage analyses. Am J Hum Genet 81:559-575

39. Ray LA, Hutchison KE (2004) A polymorphism of the mu-opioid receptor gene (oprm1) and sensitivity to the effects of alcohol in humans. Alcohol Clin Exp Res 28:1789-1795

40. Raychaudhuri SP, Raychaudhuri SK (2004) Role of ngf and neurogenic inflammation in the pathogenesis of psoriasis. Prog Brain Res 146:433-437

41. Rieder E, Tausk F (2012) Psoriasis, a model of dermatologic psychosomatic disease: psychiatric implications and treatments. Int $\mathrm{J}$ Dermatol 51:12-26

42. Rouvinen-Lagerstrom N, Lahti J, Alho H, Kovanen L, Aalto M, Partonen T, Silander K, Sinclair D, Raikkonen K, Eriksson JG, Palotie A, Koskinen S, Saarikoski ST (2013) Mu-opioid receptor gene (oprm1) polymorphism a118 g: lack of association in finnish populations with alcohol dependence or alcohol consumption. Alcohol Alcohol 48:519-525

43. Szeles G, Voko Z, Jenei T, Kardos L, Pocsai Z, Bajtay A, Papp E, Pasti G, Kosa Z, Molnar I, Lun K, Adany R (2005) A preliminary evaluation of a health monitoring programme in hungary. Eur $\mathrm{J}$ Public Health 15:26-32

44. Szigethy E, Szeles G, Horvath A, Hidvegi T, Jermendy G, Paragh G, Blasko G, Adany R, Voko Z (2012) Epidemiology of the metabolic syndrome in hungary. Pub Health 126:143-149

45. Taneda K, Tominaga M, Negi O, Tengara S, Kamo A, Ogawa H, Takamori K (2011) Evaluation of epidermal nerve density and opioid receptor levels in psoriatic itch. Br J Dermatol 165:277-284

46. Tawa EA, Hall SD, Lohoff FW (2016) Overview of the genetics of alcohol use disorder. Alcohol Alcohol 51(5):507-514

47. Tominaga M, Ogawa H, Takamori K (2007) Possible roles of epidermal opioid systems in pruritus of atopic dermatitis. J Invest Dermatol 127:2228-2235

48. Verhulst B, Neale MC, Kendler KS (2015) The heritability of alcohol use disorders: a meta-analysis of twin and adoption studies. Psychol Med 45:1061-1072

49. Zhu KJ, Zhu CY, Fan YM (2012) Alcohol consumption and psoriatic risk: a meta-analysis of case-control studies. J Dermatol 39:770-773

50. Zink A, Herrmann M, Fischer T, Lauffer F, Garzorz-Stark N, Bohner A, Spinner CD, Biedermann T, Eyerich K (2017) Addiction: an underestimated problem in psoriasis health care. J Eur Acad Dermatol Venereol 31:1308-1315

51. Zou L, Lonne-Rahm SB, Helander A, Stokkeland K, Franck J, Nordlind K (2015) Alcohol intake measured by phosphatidylethanol in blood and the lifetime drinking history interview are correlated with the extent of psoriasis. Dermatology 230:375-380

Publisher's Note Springer Nature remains neutral with regard to jurisdictional claims in published maps and institutional affiliations. 